Original article

\title{
Coronavirus disease 2019 vaccine acceptance and perceived barriers among university students in northeast Ethiopia: A cross-sectional study
}

\author{
Birhan Tsegaw Taye ${ }^{a,{ }^{*}}$, Fetene Kasahun Amogne ${ }^{a}$, Tesfanesh Lemma Demisse ${ }^{a}$, \\ Mulualem Silesh Zerihun ${ }^{\mathrm{a}}$, Tebabere Moltot Kitaw ${ }^{\mathrm{a}}$, Agumas Eskezia Tiguh ${ }^{\mathrm{b}}$, \\ Muhabaw Shumye Mihret ${ }^{\mathrm{b}}$, Azmeraw Ambachew Kebede ${ }^{\mathrm{b}}$ \\ ${ }^{a}$ Department of Midwifery, College of Medicine and Health Sciences, Debre Berhan University, Debre Berhan Ethiopia \\ ${ }^{\mathrm{b}}$ Department of Clinical Midwifery, College of Medicine and Health Sciences, University of Gondar, Gondar Ethiopia
}

\section{A R T I C L E I N F O}

\section{Keywords:}

Acceptance

COVID-19 vaccine

Ethiopia

Perceived barriers

University students

\begin{abstract}
A B S T R A C T
Background: Universities are places where students live and study in close contact to each other. Nowadays, the foundations of this particular group have been affected significantly by the rapid spread of the coronavirus disease 2019. The severity of the COVID-19 pandemic has demanded the emergency use of COVID-19 vaccines. However, there is still limited evidence in COVID-19 vaccine acceptability and perceived barriers among some subgroups, including university students. This study aimed to assess vaccine acceptance, associated factors, and perceived barriers among university students, Ethiopia.

Methods: A cross-sectional study was conducted in January 2021 at Debre Berhan University among 423 students. The participants were selected using simple random sampling technique. A semi-structured, pretested, and selfadministered questionnaire was used to collect the data. Multivariable logistic-regression model was fitted to identify factors associated with vaccine acceptance. An adjusted odds ratio with $95 \%$ confidence interval and its p-value of $\leq 0.05$ was used to declare significant association.

Results: The proportion of the COVID-19 vaccine acceptance was 69.3\% (95\% CI: 65, 74). Being knowledgeable (AOR: 2.43, CI: 1.57, 3.77), being a health science student (AOR: 2.25, CI: 1.43, 3.54), and being in a family practicing COVID-19 prevention (AOR: 1.73, CI: 1.06, 2.81) were found to be factors associated with COVID-19 vaccine acceptance.

Conclusion: Though, this study found a $69.3 \%$ acceptance of COVID-19 vaccine, there were noticeable perceived barriers and related factors in vaccine acceptance hesitancy. Thus, health education and communication regarding the vaccine are very crucial to alleviate the identified barriers.
\end{abstract}

\section{Introduction}

Institutions of higher education worldwide are undergoing distressing change because of the COVID-19 pandemic. ${ }^{1-3}$ University students are increasingly among the most strongly affected groups by the severe acute respiratory syndrome coronavirus 2 (SARS-Cov-2) infection. It is because of the university students are recognized as a vulnerable population, suffering from the pandemic due to a multitude of factors. ${ }^{2}$ Thus, the reopening of college campuses communal residency in on-campus and off-campus housing, they all feed in one cafeteria, and the necessity to travel between their home and campus during the COVID-19 pandemic. $^{4-6}$

To avert this fast spreading of coronavirus, countries worldwide have been taking different measures, such as social distancing, partial and comprehensive lockdowns, closing schools and businesses, and/or wearing face masks in public. ${ }^{7-9}$ These measures helped to flatten the pandemic curve in some countries, but the resurgence of COVID-19 has been reported as countries ease these restriction ${ }^{7,10}$ and the new variant of COVID-19 has been reported. ${ }^{11}$ Hence, there is an urgent need for safe and most effective long-term preventive measures like a

\footnotetext{
Abbreviations: COVID-19, Coronavirus Disease 2019; SARS-CoV-2, Severe Acute Respiratory Syndrome Coronavirus 2.

* Corresponding author. Department of Midwifery, College of Medicine and Health Sciences, Debre Berhan University, Box 445, Debre Birhan Ethiopia

E-mail addresses: tsegawbirhan2@gmail.com (B.T. Taye), kfetene@gmail.com (F.K. Amogne), tesfitimnt@gmail.com (T.L. Demisse), sileshmulualem22@gmail.

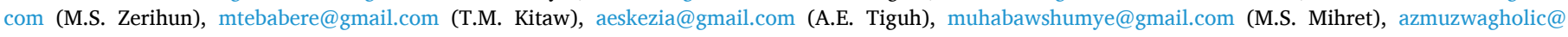
gmail.com (A.A. Kebede).
} 
vaccine. ${ }^{7-10,12-14}$ Vaccinations are a form of collective action, where herd immunity is generated by collective participation in immunization programs that is the best option to prevent the severity of the disease and its spreading. ${ }^{15}$ So, vaccination programmes can lead to herd immunity without requiring a considerable proportion of the community to be infected. Though, such immunity necessitates a sufficient proportion of the population to be vaccinated. ${ }^{16-18}$ Since the global pandemic was declared, many companies and research centres around the world have been working hard to develop effective SARS-CoV-2 vaccines. ${ }^{14}$ Vulnerable populations in all countries are the highest priority for vaccination. 8,19

Currently, national regulatory authorities have granted emergency use authorizations for 17 COVID-19 vaccines. Six of these have been approved for emergency or full use by at least one WHO-recognized stringent regulatory authority (Oxford-AstraZeneca, Pfizer-BioNTech, Sinopharm-BBIBP, Moderna, Sinovac, and Johnson \& Johnson). ${ }^{20}$ However, even the availability of the vaccine does not guarantee sufficient vaccination of the population, as demonstrated by the denial and hesitancy of the vaccine. ${ }^{18,}$ A refusal rate of more than $10 \%$ could significantly hamper the achievement of this target. ${ }^{21,22}$ A current poll reported that when a vaccine is first available in countries like America, only $50 \%,{ }^{23}$ Jordan $40.4 \%,{ }^{14}$ and United Kingdom $64 \%{ }^{8}$ of people willing to get the vaccine. In Germany, $10 \%$ of the respondents refused and $20 \%$ were unsure to be vaccinated against COVID-19. ${ }^{24}$

Scholars from other countries have recognized that many factors affect the acceptance of the COVID-19 vaccine. ${ }^{25-27}$ These include risk perception of the disease, perception of vaccine safety and efficacy, and general vaccination attitudes. ${ }^{18,28}$ Besides, history of past vaccination, doctors' recommendation, vaccination costs, vaccination convenience, and several sociodemographic characteristics are responsible for vaccine acceptancy when a new vaccine is introduced. Moreover, safety and efficacy of the vaccine, ${ }^{29-31}$ adverse health outcomes, misconceptions about the need for vaccination, lack of trust in the health system, lack of knowledge among the community on vaccine-preventable diseases were mentioned as factors of vaccine acceptance. ${ }^{11,29,32,33}$

Even though there has been a surge of articles on vaccination willingness, most of them have been conducted in the developed nations. A few studies have explored in the poorer countries particularly in African continent including Ethiopia, hence, there were noticeable demographic and geographical disparities in vaccine acceptance on a specific study population as compared racial, ethnic, and level of education. There is limited evidence on the restraining cognitive impairment to take a vaccine against COVID-19, and addressing concerns among vaccinehesitant individuals is very crucial to alleviate the negative attitude of the COVID-19 vaccine. Hence, this study intended to assess 1 ) student's anticipated level of COVID-19 vaccine acceptance 2) evaluate potential factors associated with COVID-19 vaccine acceptance and 3) perceived barriers among university students, Ethiopia. Further, this study might be very significant to discuss more appropriate and concrete policy to promote the vaccination of the population.

\section{Methods and materials}

\subsection{Study design, period, and setting}

An institution -based cross-sectional study was conducted from 20 to January 30, 2021 at Debre Berhan University, northeast Ethiopia. Debre Berhan University is one of thirteen new governmental universities founded in 2007. It is situated in the Amhara regional state, in the town of Debre Berhan which is the capital of the North-Shewa Zone, around $130 \mathrm{~km}$ far from Addis Ababa (the capital city of Ethiopia). The university had ten colleges, and fifty departments. At the moment, the university had a total number of 27,371 students: 17,397 males and 9974 females. Of these, 11,573 are regular undergraduate and postgraduate students. Overall, the University has approximately 3300 graduating class students who attend regular programs at different levels and years of study. During the design of this study, graduating class students were the first candidates for the re-admission program after COVID-19 "lockdown".

\subsection{Source and study population}

All graduating class students of Debre Berhan University were the source population, whereas graduate students during the data collection period in the university were the study population.

\subsection{Inclusion and exclusion criteria}

All graduating class students of Debre Berhan University during the data collection period were include. Because they are the first candidates during school reopening after COVID-19 "lockdown" as our focus during the proposal of this study. However, students with active SARS-CoV2 infection were excluded.

\subsection{Sample size determination}

The sample size for this study was determined by using a single proportion formula by considering the following assumptions: $50 \%$ proportion of students' willingness towards COVID-19 vaccine acceptance, 95\% level of confidence, and 5\% margin of error.

$n=\frac{Z \alpha / 2)^{2} p(1-p)}{(d)^{2}}=\frac{(1.96)^{2} * 0.5(1-0.5)}{(0.05) 2}=384$

where $\mathrm{n}=$ required sample sizes, $\alpha=$ level of significance, $\mathrm{z}=$ standard normal distribution curve value for $95 \%$ confidence level $=1.96, p=$ proportion of vaccine acceptance against COVID-19, and $d=$ margin of error. By considering a $10 \%$ non-response rate, the minimum adequate sample size was 423 .

\subsubsection{Sampling technique and procedure}

Study participants were recruited from all regular graduating class students using a simple random sampling technique (SRS). Fifteen representative departments were selected from all colleges. In each of the selected departments was selected using lottery method. A sampling frame was prepared by obtaining the list of students from the registrar office. Then, in the selected departments, the required sample size was proportionally allocated based on the total number of students. Lastly, from all students of the selected departments, SRS was done to pick the required sample size using a pre-determined sampling frame of all departments.

\subsection{Measurements and operational definitions}

Vaccine acceptance: is defined as the willingness to take the COVID-19 vaccine. ${ }^{34,35}$ Accordingly, the participants were asked their willingness to accept the COVID-19 vaccine, the possible answers were Yes or No. A score of " 1 " was given for Yes and a score of " 0 " was given for No.

Knowledgeable to COVID-19: Participants who scored above the mean (12.47) on 11 knowledge assessment questions. ${ }^{36}$

Favourable intention to practice COVID-19 prevention measures: Based on the summative scores designed to assess intention of COVID-19 prevention practice. Each item has "Always", "Occasionally" or "Never", response giving a score of $0-8$; a score above the mean (4.65) was considered as favourable intention. ${ }^{37}$

Good COVID-19 prevention practice: A total of 13 items were prepared to assess COVID-19 preventive practice which each item has "Always", "Occasionally" or "Never" alternatives, response giving a score of $0-26$. Based on summative score above the mean (12.57) considered as good preventive practice. ${ }^{38}$ 


\subsection{Data collection tools and procedures}

A structured, pretested, and self-administered questionnaire was used to collect the data. Socio-demographic characteristics, knowledge and COVID-19 prevention practice-related characteristics were included in the study tool. Two Bachelor of Science and two Master of Science in midwifery holders were recruited for data collection and supervision respectively. To minimize further risks of COVID-19 transmission, data collectors and participants were following the precautionary measures as per the guidelines for the prevention of COVID-19.

\subsection{Data quality control}

The questions prepared in English were initially translated into Amharic and then again into English to ensure consistency. It was prevalidated by three independent reviewers, and a pre-test study was conducted with $5 \%$ of the sample size outside the study area. The data collectors and supervisors received a one-day training regarding the objective of the study, the procedures, and the necessary precautions, the means to collect, and keep confidential the information obtained from the respondents before the actual data collection.

\subsection{Data processing and analysis}

The data was verified, coded, and captured in Epi Data version 4.6 and exported to SPSS version 25 for analysis. Descriptive statistics were used to describe participants' characteristics. Candidate variables were identified by cross-tabulation and proceeded to bivariable logistic regression analysis. Thereafter, all explanatory variables were included in the multivariable logistic regression analysis model to handle the effect of possible confounders and to identify independent factors affecting vaccine acceptance against COVID-19. The adjusted odds ration with its $95 \%$ confidence interval (CI) and a p-value of $\leq 0.05$ was used to declare significant statistical analysis.

\subsection{Ethical approval and consent to participate}

The study was conducted under the declaration of Helsinki. Ethical clearance was obtained from the Institutional Ethical Review Board (IRB) of Debre Berhan University (protocol number: P006/20). Anonymous informed consent was taken from each participant after a clear description of the aim of the study and it was done following the principles of declaration of Helsinki.

\section{Result}

\subsection{Socio-demographic characteristics}

A total of 423 students were participate in this study, giving a $100 \%$ response rate. The mean age of the study subjects was 24.17 years (SD \pm 1.73) and more than half of the respondents were below the age of 25 years. Most of the respondents were male (66.4\%), health science students $(68.3 \%)$, and come from a rural area (58.2\%). More than fourfifths of the participants had a smartphone. Regarding the educational status of respondents' families, $67.1 \%$ of mothers and $58.2 \%$ fathers had no formal education (Table 1 ).

\subsection{Participant's knowledge about COVID-19, intention, and practice towards its prevention}

As shown in Table 2, 63.1\% of participants were knowledgeable about coronavirus, $54.8 \%$ had favourable intentions for COVID- 19 prevention measures, and slightly more than half (51.5\%) of participants were practicing prevention measures appropriately.
Table 1

Participants' demographics $(\mathrm{n}=423)$.

\begin{tabular}{|c|c|}
\hline Variables & n (\%) \\
\hline \multicolumn{2}{|l|}{ Age (in years) } \\
\hline$<25$ & $245(57.9)$ \\
\hline$\geq 25$ & $178(42.1)$ \\
\hline \multicolumn{2}{|l|}{$\overline{S e x}$} \\
\hline Male & $281(66.4)$ \\
\hline Female & $142(33.6)$ \\
\hline \multicolumn{2}{|l|}{ Field of study } \\
\hline Health & $289(68.3)$ \\
\hline Non-health & $134(31.7)$ \\
\hline \multicolumn{2}{|l|}{ Residence comes from } \\
\hline Rural & $246(58.2)$ \\
\hline Urban & $177(41.8)$ \\
\hline \multicolumn{2}{|l|}{ Marital status } \\
\hline Single & $305(72.1)$ \\
\hline Married & $48(11.3)$ \\
\hline In relationship & $70(16.5)$ \\
\hline \multicolumn{2}{|c|}{ Average monthly income gained in Ethiopian birr } \\
\hline$<500$ & $134(31.7)$ \\
\hline $500-999$ & $153(36.2)$ \\
\hline$\geq 1000$ & $136(32.2)$ \\
\hline \multicolumn{2}{|l|}{ Do you have a smartphone? } \\
\hline Yes & $350(82.7)$ \\
\hline No & $73(17.3)$ \\
\hline \multicolumn{2}{|l|}{ Mothers' educational status } \\
\hline No formal education & $284(67.1)$ \\
\hline Formal education (1-12 Grades) & $114(27.0)$ \\
\hline College and above & $25(5.9)$ \\
\hline \multicolumn{2}{|l|}{ Fathers' educational status } \\
\hline No formal education & $246(58.2)$ \\
\hline Formal education (1-12 Grades) & $119(28.1)$ \\
\hline College and above & $58(13.7)$ \\
\hline \multicolumn{2}{|c|}{ Do your family members use COVID-19 prevention methods? } \\
\hline Yes & $321(75.9)$ \\
\hline No & $102(24.1)$ \\
\hline \multicolumn{2}{|c|}{ Do your family members ever infect with COVID-19? } \\
\hline Yes & $52(12.3)$ \\
\hline No & $371(87.7)$ \\
\hline
\end{tabular}

Table 2

Participant's knowledge about COVID-19, intention, and practice towards its prevention $(\mathrm{n}=423)$.

\begin{tabular}{lc}
\hline Categories & $\mathrm{n}(\%)$ \\
\hline $\begin{array}{l}\text { Knowledge of the participant } \\
\text { Not knowledgeable }\end{array}$ & $156(36.9)$ \\
$\begin{array}{l}\text { Knowledgeable } \\
\text { Participant's intention towards COVID-19 prevention }\end{array}$ & $267(63.1)$ \\
Unfavorable intention & $191(45.2)$ \\
Favourable intention & $232(54.8)$ \\
Participant's COVID-19 prevention practice & \\
Inappropriate practice & $205(48.5)$ \\
Good COVID-19 prevention practice & $218(51.5)$ \\
\hline
\end{tabular}

\subsection{Willingness to be vaccinated against COVID-19 and perceived barriers}

From the total study participants, 293 (69.3\% (95\% CI: 65, 74)) were willing to the vaccine against COVID-19. The main reasons (perceived barriers) for participants' unwillingness to be vaccinated were perceived less individual risk $58 \%$; the uncertainty of vaccine effectiveness $52 \%$; had concern on side effects $68 \%$; had a need to know more about the vaccine $48 \%$, and perceived the vaccine only for those who are at risk 44\% (Fig. 1).

\subsection{Factors associated with COVID-19 vaccine acceptance}

The association between covariates with response variables was estimated by the odds ratio using logistic regression analysis. Being in the medical health field, having family members practicing COVID-19 


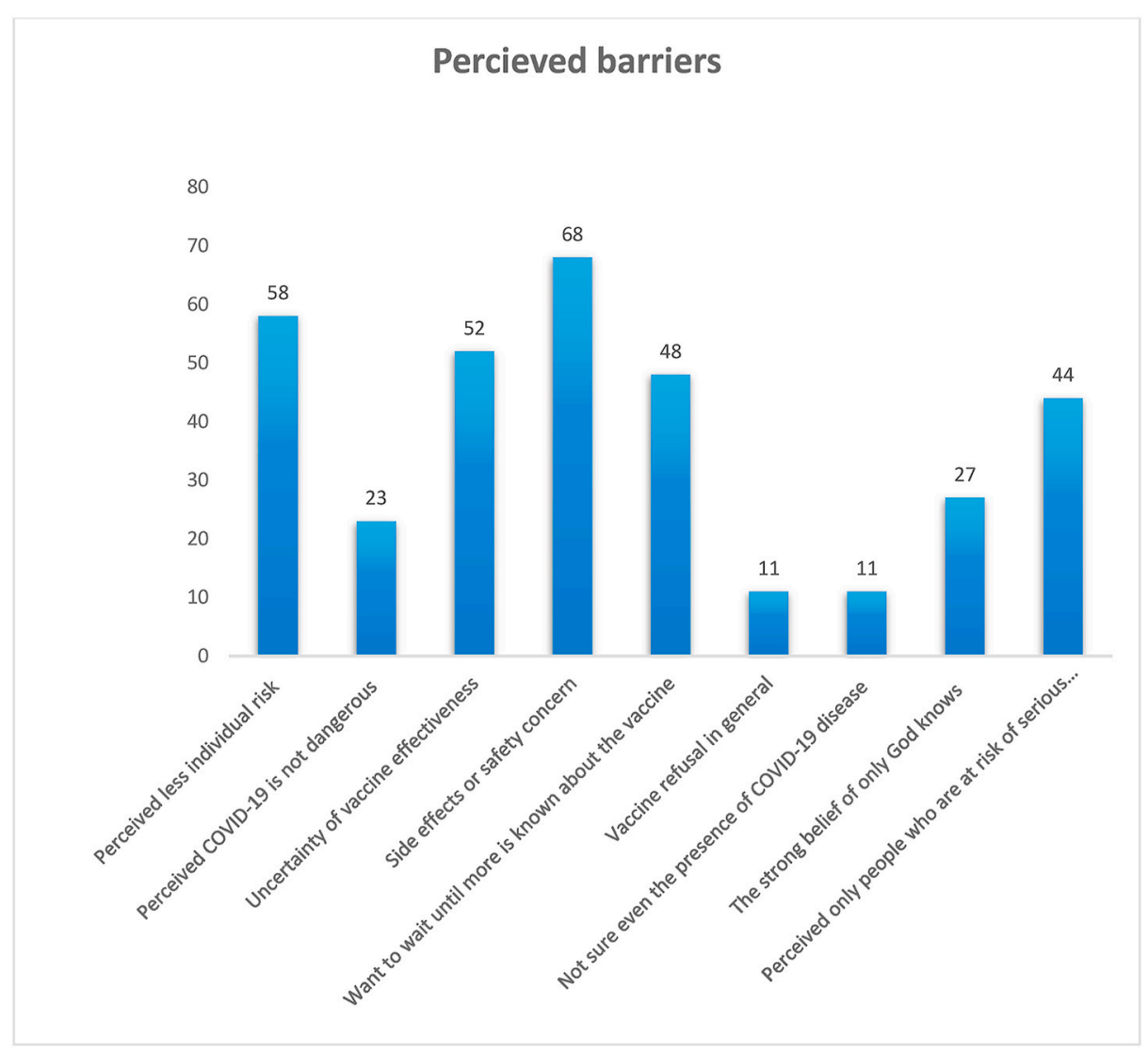

Fig. 1. Main reasons for not willing for COVID-19 vaccine acceptance among university students.

prevention methods, and being knowledgeable had a positive significant association with COVID-19 vaccine acceptance. There were no differences by gender, age, intention to COVID-19 preventions, had family members infected with coronavirus, and families' educational levels and concerns related to intent of COVID-19 prevention (Table 3).

In this study, knowledgeable participants were 2.43 times more likely to accept the COVID-19 vaccine (AOR: 2.43, CI: 1.57, 3.77). Participants studying in the medical health field were twice more likely willing to accept the vaccine (AOR: 2.25 , CI: 1.43, 3.54). The odds of having had family members who was used to COVID-19 prevention practice were 1.73 time's higher vaccine acceptance than their counterparts (AOR: 1.73, CI: 1.06, 2.81) (Table 3).

\section{Discussion}

Implementation of COVID-19 vaccination needs to have adequate willingness of the population to tackle the global repercussions of the pandemic. This study assessed Debre Berhan University students' COVID-19 vaccine acceptance, the factors that influence their willingness and perceived barriers. Thus, the overall proportion of COVID-19 vaccine acceptance was $69.3 \%$. This finding is slightly higher than a previous study conducted in United Kingdom in which $64 \%$ of participants had good vaccine acceptance against COVID-19. ${ }^{8}$ This might be due to difference in the study population. Hence, this study includes university students in which their level of understanding and comprehension might be higher compared to the general population. A similar finding was reported in China where students were more likely to get the COVID-19 vaccine. ${ }^{39}$ This result is also similar to previous studies conducted in the United States $(69 \%, 67 \%),{ }^{40,41}$ Canada $68.2 \%,{ }^{42}$ and Belgium $73 \% .{ }^{10}$ However, the result of this study is higher as compared to previous studies conducted in the United Kingdom- $64 \%,{ }^{8}$ Saudi Arabia-64.7\%, ${ }^{29}$ United Kingdom- $63.5 \%,{ }^{43}$ and Greece- $57.7 \%{ }^{33}$ The discrepancy might be attributed to variation in the time gap, sociodemographic characteristics, level of knowledge regarding COVID-19, and the study population. The present study includes university students whereas the above-mentioned studies were conducted among the general population. We expect university students will have better information about COVID-19, regular updates concerning COVID-19, and they tend to have good media exposure. Evidence indicated that regular exposure to media increases an individual's knowledge of COVID-19 thereby willing to be vaccinated against it. ${ }^{44}$ Likewise, a study from China found that students had a higher acceptance to be vaccinated against COVID-19. ${ }^{39}$ Moreover, good adherence to recommend COVID-19 preventive measures had a significant contribution to have a good acceptance to take COVID-19 vaccine. ${ }^{43}$ Hence, slightly more than half of the students in this study had a good COVID-19 prevention practice.

On the contrary, the result of the present study was lower compared with other previous studies conducted in Denmark $(79 \%)^{45}$ and Australia $(85.5 \%) .{ }^{46}$ The variation might be ascribed to differences in sociodemographic contexts and study settings. The habit of media utilization, culture, and religious beliefs might have a great influence on willingness to get the COVID-19 vaccine. ${ }^{16,47}$ The other explanation might be the perceived barriers towards the vaccine. ${ }^{48}$ In the present study, more than two-thirds and slightly more than half of the participants who were not accept the vaccine due to perceived vaccine side effects and uncertainty about its effectiveness respectively. In this regard, the concerned stakeholders such as the federal ministry of health, the regional health bureau, and the Media should disseminate factual information to the community thereby building trust, having a wide coverage of vaccination, and eliminating the pandemic in the long run. Moreover, about a third of participants in the current study were not willing to receive the COVID-19 vaccine. Similar findings were reported in Nigeria-30.5\%, ${ }^{15}$ Jordan-39.5\%, 36.3\%, ${ }^{14,49}$ and France- $35 \% .{ }^{50}$ 
Table 3

Bivariable and multivariable analysis of variables on COVID-19 vaccine acceptance $(\mathrm{n}=423)$.

\begin{tabular}{|c|c|c|c|c|}
\hline \multirow[t]{2}{*}{ Variables } & \multicolumn{2}{|c|}{$\begin{array}{l}\text { COVID-19 } \\
\text { vaccine } \\
\text { acceptance }\end{array}$} & \multirow[t]{2}{*}{$\begin{array}{l}\text { COR }(95 \% \\
\text { CI) }\end{array}$} & \\
\hline & Yes & No & & \\
\hline \multicolumn{5}{|l|}{ Age (in years) } \\
\hline$<25$ & 168 & 77 & 1 & 1 \\
\hline$\geq 25$ & 125 & 53 & $\begin{array}{l}1.08(0.71 \\
1.64)\end{array}$ & $\begin{array}{l}0.83(0.54, \\
1.3)\end{array}$ \\
\hline \multicolumn{5}{|l|}{ Sex } \\
\hline Male & 191 & 90 & 1 & 1 \\
\hline Female & 102 & 40 & $\begin{array}{l}1.2(0.77 \\
1.87)\end{array}$ & $\begin{array}{l}1.0(0.59, \\
1.68)\end{array}$ \\
\hline \multicolumn{5}{|l|}{ Place of residence } \\
\hline Rural & 163 & 83 & 1 & 1 \\
\hline Urban & 130 & 47 & $\begin{array}{l}1.41(0.92 \\
2.16)\end{array}$ & $\begin{array}{l}1.1(0.65 \\
1.85)\end{array}$ \\
\hline \multicolumn{5}{|l|}{ Field of study } \\
\hline Medical/Health & 217 & 72 & $\begin{array}{l}2.3(1.49, \\
3.55)\end{array}$ & $\begin{array}{l}2.25(1.43, \\
3.54)^{* *}\end{array}$ \\
\hline \multicolumn{5}{|l|}{ Marital status } \\
\hline Single & 211 & 94 & 1 & 1 \\
\hline Married & 36 & 12 & $\begin{array}{l}1.34(0.67 \\
2.68)\end{array}$ & $\begin{array}{l}1.12(0.53 \\
2.38)\end{array}$ \\
\hline In relationship & 46 & 24 & $\begin{array}{l}0.85(0.49 \\
1.48)\end{array}$ & $\begin{array}{l}0.75(0.41 \\
1.36)\end{array}$ \\
\hline \multicolumn{5}{|l|}{ Do you have a smartphone? } \\
\hline Yes & 245 & 105 & $\begin{array}{l}1.22(0.71 \\
2.07)\end{array}$ & $\begin{array}{l}1.02(0.57, \\
1.84)\end{array}$ \\
\hline No & 48 & 25 & 1 & 1 \\
\hline \multicolumn{5}{|l|}{ Mothers' educational status } \\
\hline No formal education & 187 & 97 & 1 & 1 \\
\hline Formal education (1-12 Grades) & 85 & 29 & $\begin{array}{l}1.52(0.93 \\
2.48)\end{array}$ & $\begin{array}{l}1.21(0.72, \\
2.0)\end{array}$ \\
\hline College and above & 21 & 4 & $\begin{array}{l}2.72(0.91 \\
8.16)\end{array}$ & $\begin{array}{l}2.63(0.84, \\
8.18)\end{array}$ \\
\hline \multicolumn{5}{|l|}{ Fathers' educational status } \\
\hline No formal education & 161 & 85 & 1 & 1 \\
\hline Formal education (1-12 Grades) & 87 & 32 & $\begin{array}{l}1.44(0.89 \\
2.33)\end{array}$ & $\begin{array}{l}0.96(0.52 \\
1.76)\end{array}$ \\
\hline College and above & 45 & 13 & $\begin{array}{l}1.83(0.93 \\
3.57)\end{array}$ & $\begin{array}{l}1.06(0.43 \\
2.59)\end{array}$ \\
\hline \multicolumn{5}{|l|}{$\begin{array}{l}\text { Do family members use COVID- } \\
19 \text { prevention methods? }\end{array}$} \\
\hline Yes & 234 & 87 & $\begin{array}{l}1.96(1.23 \\
3.12)\end{array}$ & $\begin{array}{l}1.73(1.06, \\
2.81) *\end{array}$ \\
\hline No & 59 & 43 & 1 & 1 \\
\hline \multicolumn{5}{|l|}{$\begin{array}{l}\text { Do family members ever infect } \\
\text { with COVID-19? }\end{array}$} \\
\hline Yes & $\begin{array}{l}40 \\
(13.7)\end{array}$ & 12 & $\begin{array}{l}1.56(0.79 \\
3.07)\end{array}$ & $\begin{array}{l}1.63(0.78, \\
3.39)\end{array}$ \\
\hline No & $\begin{array}{l}253 \\
(86.3)\end{array}$ & 118 & 1 & 1 \\
\hline \multicolumn{5}{|l|}{ Knowledge of the participant } \\
\hline Not knowledgeable & 90 & 66 & 1 & 1 \\
\hline Knowledgeable & 203 & 64 & $\begin{array}{l}2.33(1.52, \\
3.56)\end{array}$ & $\begin{array}{l}2.43(1.57, \\
3.77) * *\end{array}$ \\
\hline \multicolumn{5}{|l|}{$\begin{array}{l}\text { Participant's intention towards } \\
\text { COVID-19 prevention }\end{array}$} \\
\hline Unfavorable intention & 132 & 59 & 1 & 1 \\
\hline Favourable intention & 161 & 71 & $\begin{array}{l}1.01(0.67 \\
1.54)\end{array}$ & $\begin{array}{l}0.97(0.62, \\
1.52)\end{array}$ \\
\hline \multicolumn{5}{|l|}{$\begin{array}{l}\text { Participant's COVID-19 } \\
\text { prevention practice }\end{array}$} \\
\hline Inappropriate practice & 146 & 59 & 1 & 1 \\
\hline Appropriate practice & 147 & 71 & $\begin{array}{l}0.84(0.55 \\
1.27)\end{array}$ & $\begin{array}{l}0.98(0.62, \\
1.56)\end{array}$ \\
\hline
\end{tabular}

$* \mathrm{p}<0.05,{ }^{* *} \mathrm{p} \leq 0.001$

In this study, having adequate knowledge of COVID-19 was significantly associated with student's willingness to accept the COVID-19 vaccine. Accordingly, those students who had good knowledge of COVID-19 were 2.43 times more likely to have had good acceptance against COVID-19 vaccine as compared to those students having inadequate knowledge. This finding is consistent with a study conducted in Greece ${ }^{33}$ and United Kingdom. ${ }^{43}$ This could be explained by knowledge is the start-up point for any practice and an engine to take actions regarding a certain behaviour. Besides, knowledgeable individuals may understand the seriousness of the disease and the need to eliminate the virus ultimately using all the available opportunities like vaccines.

This study also revealed that being a health science student increases the odds of having good COVID-19 vaccine acceptance. Thus, those students studying health science fields were two times more likely to have had a good willingness to accept the COVID-19 vaccine compared with students studying non-health departments. This might be since health science students are more familiar with the signs and symptoms of COVID-19; they will easily understand the long-term costs of the pandemic. Moreover, they are near to health facilities/hospitals and highly exposed to different population due to the nature of their education. In connection to this, students may experience fear and frustration not to be infected by COVID-19. This furthers enables them to consider themselves as a high-risk group thereby accepting the vaccine and willing to be vaccinated against the disease.

This study depicts that students in family members practicing COVID-19 prevention methods were 1.73 times more likely to have had vaccine acceptance against COVID-19 as compared to their counterparts. In this case, families may advise their children the need for strictly following COVID-19 preventive measures and the need for vaccination against the disease. Moreover, most partners might have good compliance with COVID-19 preventive methods in order not to infect their children. So, children may consider it as their families are still worried about them and may decide to be vaccinated against COVID-19 considering they are helping their families. This study also identified that perceiving less individual risk (58\%), the uncertainty of vaccine effectiveness (52\%), concern on side effects, a need to know more about the vaccine (48\%), and perceived the vaccine only for those who are at risk (44\%) were the main reasons mentioned by the study participants for COVID-19 vaccine hesitancy.

Lastly, the authors acknowledged the following limitations. First, the study was conducted in a special geographic region, so it might not be representative of the general population. However, since students are part of the community, they might reflect intentions in the community. Second, the cross-sectional nature of the study design doesn't show the causal association. Lastly, since the study was self-reported, it is highly imposed to response bias.

\section{Conclusion}

More than two-thirds of the study participants were willing to accept COVID-19 vaccine. The likelihood of accepting the COVID-19 vaccine was higher among knowledgeable, being a health science student, and being in a family members practicing COVID-19 preventive measures. Moreover, COVID-19 vaccine refusal concerns were perceived less individual COVID-19 risk, the uncertainty of vaccine effectiveness, fear of side effects, the need to know more about the vaccine, and perceiving the vaccine is only for risky individuals. In this regard, the evidence from this finding calls upon policymakers and program managers to play a major role in implementing an integrated approach of health education and communication for a greater effect on negative perceived barriers of COVID-19 vaccine. Further triangulated studies may be advisable to address behavioral perceived barriers with a larger sample size.

\section{Data sharing statement}

The data sets used and/or analysed in the present study are available from the corresponding author upon reasonable request. 


\section{Funding}

No funding was used to assist in the preparation of this study.

\section{Authors' contributions}

BT select the title, develop the proposal, and participate in data entry and analysis. All authors participated in manuscript preparation, revision, and approved the manuscript to be considered for publication.

\section{Declaration of competing interest}

The author reports no conflicts of interest in this work.

\section{Acknowledgments}

We would like to thank Debre Berhan University for its ethical authorization. Our compliment is also extended to study participants, data collectors, and supervisors for their friendly cooperation.

\section{References}

1 Dennis MJ. Coronavirus Crisis and HE. Univ world news. Published online 2020:155. https://www.universityworldnews.com/page.php?page=Coronavirus_Hub.

2 Aristovnik A, Keržič D, Ravšelj D, Tomaževič N, Umek L. Impacts of the COVID-19 pandemic on life of higher education Students : a global perspective. Preprint. 2020; (August):1-35. https://doi.org/10.20944/preprints202008.0246.v2.

3 Sharma M, Davis RE, Wilkerson AH. COVID-19 vaccine acceptance among college Students : a theory-based analysis. Environ Reaserch public Heal. 2021;18:17. https:// doi.org/10.3390/ijerph18094617.

$4 \mathrm{Ihm}$ L, Zhang H, Vijfeijken A Van, Waugh MG. Impacts of the Covid - 19 pandemic on the health of university students. Int J Heal Plann Mgmt. 2021;36(February):618-627. https://doi.org/10.1002/hpm.3145.

5 Browning MHEM, Larson LR, Sharaievska I, et al. Psychological impacts from COVID19 among university students: risk factors across seven states in the United States. PloS One. 2021;16(1):1-27. https://doi.org/10.1371/journal.pone.0245327.

6 Holzer J, Pelikan, Marko Lüftenegger, Korlat Selma, Katariina Elisabeth, Katariina Salmela-Aro CSBS. Higher education in times of COVID-19: university students' basic need satisfaction, self-regulated learning, and well-being. SAGE. 2021;7(1):1-13. https://doi.org/10.1177/23328584211003164.

7 Guidry JPD, Laestadius LI, Vraga EK, et al. Willingness to get the COVID-19 vaccine with and without emergency use authorization. Am J Infect Contr. 2021;49(2): 137-142. https://doi.org/10.1016/j.ajic.2020.11.018.

8 Sherman SM, Smith LE, Sim J, et al. COVID-19 vaccination intention in the UK : results from the COVID-19 vaccination acceptability study ( CoVAccS ), a nationally representative cross- sectional survey. Hum Vaccines Immunother. 2020:1-10. https:// doi.org/10.1080/21645515.2020.1846397.

9 Chen M, Li Y, Chen J, et al. An online survey of the attitude and willingness of Chinese adults to receive COVID-19 vaccination. Hum Vaccines Immunother. 2021: 1-10. https://doi.org/10.1080/21645515.2020.1853449.

10 Tubeuf S, Kessels R, Luyten J, Tubeuf S. Willingness to get vaccinated against covid19: profiles and attitudes towards vaccination. UCLouvain. Published online. 2020: $1-10$.

11 Srichan P, Apidechkul T, Tamornpark R, et al. Knowledge, attitudes and preparedness to respond to COVID-19 among the border population of northern Thailand in the early period of the pandemic: a cross-sectional study. WHO SouthEast Asia J public Heal. 2020;9(2):118-125. https://doi.org/10.4103/22243151.294305.

12 García LY, Cerda AA. Contingent assessment of the COVID-19 vaccine. Vaccine. 2020; 38(34):5424-5429. https://doi.org/10.1016/j.vaccine.2020.06.068.

13 Magadmi RM. Beliefs and Barriers Associated with COVID-19 Vaccination Among the General Population in Saudi Arabia. 2020. https://doi.org/10.21203/rs.3.rs-48955/v1 License.

14 Almaaytah A, Salama A. Acceptance of COVID-19 vaccination among Jordanian Adults : a cross sectional study. Syst Rev Pharm. 2021:11(11):1291-1297.

15 Chiedozie AP, Chukwuebuka OJ, Chidimma CF, Gabriel OC, Chioma UB. Willingness to accept a potential COVID-19 vaccine in Nigeria. Am J Med Sci Med. 2021;9(1):1-5. https://doi.org/10.12691/ajmsm-9-1-1.

16 Alwi SARS, Rafidah E, Zurraini A, Juslina O, Brohi IB, Lukas S. A survey on COVID19 vaccine acceptance and concern among Malaysians. BMC Publ Health. 2021;21: 1-12. https://doi.org/10.1186/s12889-021-11071-6.

17 Malik AA, Mcfadden SM, Elharake J, Omer SB. Determinants of COVID-19 vaccine acceptance in the US. EClinicalMedicine. 2020;26:100495. https://doi.org/10.1016/j. eclinm.2020.100495.

18 Paudel S, Palaian S, Subedi N. Risk perception and hesitancy toward COVID-19 vaccination among healthcare workers and staff at a medical college in Nepal. Risk Manag Healthc Pol. 2021;14:2253-2261.

19 World Health Organization (WHO). COVID-19 Vaccines.; 2021.
20 World Health Organization (WHO). Status of COVID-19 Vaccines within WHO EUL/PQ Evaluation Process; 2021. https://extranet.who.int/pqweb/sites/default/files/docu ments/Status_COVID_VAX_18May2021.pdf.

21 Dror AA, Eisenbach N, Taiber S, et al. Vaccine hesitancy: the next challenge in the fight against COVID-19. Eur J Epidemiol. 2020;35(8):775-779. https://doi.org/ 10.1007/s10654-020-00671-y.

22 Schaffer Deroo S, Pudalov NJ, Fu LY. Planning for a COVID-19 vaccination program. JAMA, J Am Med Assoc. 2020;323(24):2458-2459. https://doi.org/10.1001/ jama.2020.8711.

23 Mccarthy T. Just Half of Americans Plan on Getting Covid-19 Vaccine, Poll Shows | Coronavirus | the Guardian. The Guardian; 2021, 2020-2022.

24 Grüner S, Krüger F. The intention to be vaccinated against COVID-19: stated preferences before vaccines were available. Appl Econ Lett. 2020:1-5. https://doi. org/10.1080/13504851.2020.1854445, 00(00).

25 Paul E, Steptoe A, Fancourt D. Attitudes towards vaccines and intention to vaccinate against COVID-19 : implications for public health communications. Lancet. 2021;10: 12. https://doi.org/10.1016/j.lanepe.2020.100012.

26 Kelly BJ, Southwell BG, Mccormack LA, et al. Correction to : predictors of willingness to get a COVID-19 vaccine in the U . S. BMC Infect Dis. 2021;21:12879.

27 Shekhar R, Sheikh AB, Upadhyay S, Singh M, Kottewar S. COVID-19 vaccine acceptance among health care workers in the United States. Vaccine. 2021;9:1-15.

28 Handebo S, Adugna A, Kassie A, Shitu K. Determinants of COVID-19-related knowledge and preventive behaviours among students in reopened secondary schools: cross-sectional study. BMJ Open. 2021;11(April 2020):1-10. https://doi. org/10.1136/bmjopen-2021-050189.

29 Al-Mohaithef M, Padh BK. Determinants of COVID-19 vaccine acceptance in Saudi Arabia: a web-based national survey. $J$ Multidiscip Healthc. Published online. 2020: 1657-1663. https://doi.org/10.1101/2020.05.22.20110700.

30 Zhou Y, Liang M. Willingness to Receive Future Covid-19 Vaccines Following the Covid19 Epidemic in Shanghai, China. 2021. https://doi.org/10.21203/rs.3.rs-118731/v1 License.

31 Dzieciolowska S, Hamel D, Gadio S, et al. Covid-19 vaccine acceptance, hesitancy, and refusal among Canadian healthcare workers : a multicenter survey. Am J Infect Contr. 2021:1-6. https://doi.org/10.1016/j.ajic.2021.04.079.

32 Alqudeimat Yosor, Alenezi Deema, AlHajri Bedour, et al. Acceptance of a COVID-19 vaccine and its related determinants among the general adult population in Kuwait. Med Princ Pract. 2021;17:23. https://doi.org/10.1159/000514636.

33 Kourlaba G, Kourkouni E, Maistreli S, et al. Willingness of Greek general population to get a COVID-19 vaccine. Glob Heal Res Policy. 2021;6(1):1-10. https://doi.org/ 10.1186/s41256-021-00188-1.

34 Dubé E, Bettinger J, Fisher W, Naus M, Mahmud S, Hilderman T. Vaccine acceptance, hesitancy and refusal in Canada: challenges and potential approaches. Can Comm Dis Rep. 2016;42(12):246-251. https://doi.org/10.14745/ccdr.v42i12a02.

35 Coustasse A, Kimble C, Maxik K. COVID-19 and vaccine hesitancy: a challenge the United States must overcome. J Ambul Care Manag. 2021;44(1):71-75. https://doi. org/10.1097/JAC.0000000000000360.

36 W/Mariam Tg, Ayanaw BK, Asratie MH, Abate AT. The effects of fear and knowledge of COVID-19 on preventive practice among pregnant women who attend antenatal care in northwest Ethiopia , 2020 : institution-based cross-sectional study. Doc Guid. 2021;13:95-100. https://doi.org/10.2147/IJWH.S286088.

37 Andarge E, Fikadu T, Temesgen R, et al. Intention and practice on personal preventive measures against the COVID-19 pandemic among adults with chronic conditions in southern Ethiopia : a survey using the theory of planned behavior. J Multidiscip Healthc. 2020;13:1863-1877. https://doi.org/10.2147/JMDH.S284707.

38 Jackson D. University Prep Academy COVID-19 Preparedness and Response Plan; 2020. https://uprepschools.com/wp-content/uploads/2020/08/UPA-COVID-19-Prepare dness-Response-Plan.pdf.

39 Gan L, Chen Y, Hu P, et al. Willingness to receive sars-cov-2 vaccination and associated factors among Chinese adults: a cross sectional survey. Int $J$ Environ Res Publ Health. 2021;18(4):1-11. https://doi.org/10.3390/ijerph18041993.

40 Reiter PL, Pennell ML, Katz ML. Acceptability of a COVID-19 vaccine among adults in the United States: how many people would get vaccinated? Vaccine. 2020;38(42): 6500-6507. https://doi.org/10.1016/j.vaccine.2020.08.043.

41 Malik AA, McFadden SAM, Elharake J, Omer SB. Determinants of COVID-19 vaccine acceptance in the US. EClinicalMedicine. 2020;26:100495. https://doi.org/10.1016/j. eclinm.2020.100495.

42 Frank K, Arim R. Canadians ' willingness to get a COVID-19 vaccine when one becomes available : what role does trust play? STATCAN COVID-19 Data to Insights a Better Canada. 2020;(45280001):1-6.

43 Paul E, Steptoe A, Fancourt D. Attitudes towards vaccines and intention to vaccinate against COVID-19 : implications for public health communications. Lancet Reg Heal Eur. 2021;1. https://doi.org/10.1016/j.lanepe.2020.100012.

44 Liu L, Xie J, Li K, Ji S. Exploring how media influence preventive behavior and excessive preventive intention during the COVID-19 pandemic in China. Int $J$ Environ Res Publ Health. 2020;17(21):1-27. https://doi.org/10.3390/ijerph17217990.

45 Ardens S. DANES are the most willing to be vaccinated. Carlsbergfondet. 2021:1-5

46 Dodd RH, Cvejic E, Bonner C, et al. Willingness to vaccinate against COVID-19 in Australia. Lancet Infect Dis. 2020;3099(20):30559. https://doi.org/10.1016/S14733099(20)30559-4.

47 Echoru I, Ajambo PD, Keirania E, Bukenya EEM. Sociodemographic factors associated with acceptance of COVID-19 vaccine and clinical trials in Uganda : a cross-sectional study in western Uganda. BMC Publ Health. 2021;21:1-8. https://doi. org/10.1186/s12889-021-11197-7. 
48 Kanyike AM, Olum R, Kajjimu J, et al. Acceptance of the coronavirus disease- 2019 vaccine among medical students in Uganda. Trop Med Health. 2021;49(37):1-11. https://doi.org/10.1186/s41182-021-00331-1.

49 El-Elimat T, AbuAlSamen MM, Almomani BA, Al-Sawalha NA, Alali FQ. Acceptance and Attitudes toward COVID-19 Vaccines : A Cross-Sectional Study from Department of Medicinal Chemistry and Pharmacognosy, Faculty of Pharmacy, Jordan
University of Science and Technology , Irbid 22110 , Jordan Department of Family and Commun. MedRxiv. Published online 2020:1-18.

50 Detoc M, Bruel S, Frappe P, Tardy B, Botelho-Nevers E, Gagneux-Brunon A. Intention to participate in a COVID-19 vaccine clinical trial and to get vaccinated against COVID-19 in France during the pandemic. Vaccine. 2020;38(45):7002-7006. https:// doi.org/10.1016/j.vaccine.2020.09.041. 